\title{
GBS colonization: prevalence and the impact of smoking in women delivering term or near term neonates in a large tertiary care hospital; a retrospective chart review
}

\author{
Philip Kum-Nji ${ }^{1}$, Linda Meloy ${ }^{2}$, John Pierce ${ }^{3}$, Amanda Ritter ${ }^{4}$, and Rachel Wheeler ${ }^{4}$ \\ ${ }^{1}$ Children's Hospital of Richmond at Virginia Commonwealth University \\ ${ }^{2}$ Affiliation not available \\ ${ }^{3}$ Lynchburg General Hospital \\ ${ }^{4}$ Virginia Commonwealth University School of Medicine
}

May 12, 2020

\begin{abstract}
Objective We explored the association of smoking and GBS colonization among women delivering neonates 35 weeks+. Design Retrospective chart review Setting A large tertiary care inner-city hospital in the southern United States Population/Sample 803 women pregnant women of term or near term neonates Methods The electronic health records of a convenience sample. Main Outcome Measures The outcome variable of interest was maternal GBS colonization. The primary independent variable of interest was tobacco smoking during pregnancy. Results The prevalence of maternal GBS colonization was $32 \%$ among the study population. In the univariate analyses, factors associated with maternal GBS colonization were tobacco smoking during pregnancy ( $\mathrm{P}$ of trend $<0.001$ ), Race (African Americans with the highest colonization rates and East Asians the lowest; $\mathrm{P}<0.001)$, maternal age $<20$ years $(\mathrm{P}=0.006)$, low birthweight $<2500$ gm $(\mathrm{P}=0.02)$, maternal drug use $(\mathrm{P}=004)$, and gestational age $<37(\mathrm{P}=0.041)$. Gestational diabetes, parity, and gender were not predictive of GBS colonization. In the multiple logistic regression analysis, Women who smoked during pregnancy were more than twice more likely to be colonized than their nonsmoking counterparts $(\mathrm{OR}=2.6 ; 95 \% \mathrm{CI}=1.5-4.6 ; \mathrm{p}<0.001)$. Maternal age was the only other significant predictor with young mothers $<20$ years more than one and a half time more likely to be colonized than their older counterparts $(\mathrm{OR}=1.65$; 95\% CI=1.02-2.68; $\mathrm{P}=0.04$ ). Conclusion Smoking during pregnancy was identified as an independent risk factor for GBS colonization. This is another reason that women should refrain from smoking during pregnancy to avoid risking their babies developing GBS disease.
\end{abstract}

GBS colonization: prevalence and impact of smoking in women delivering term or near term neonates in a large tertiary care hospital; a retrospective chart review

Smoking during pregnancy and GBS colonization

Philip Kum-Nji, ${ }^{*}$ Linda Meloy, ${ }^{a}$ John Pierce, ${ }^{\text {b }}$ Amanda Ritter, ${ }^{\text {c Rachel Wheeler, }}{ }^{c}$

* Children's Hospital of Richmond at the Virginia Commonwealth University School of Medicine, Richmond, Virginia, United States of America

b Lynchburg Women's Health, Lynchburg, Virginia, United States of America,

c Department of Obstetrics and Gynecology, Virginia Commonwealth University School of Medicine, Richmond, Virginia, United States of America

* Correspondence: Children's Hospital of Richmond at the Virginia Commonwealth University School of Medicine, 1000 E Broad Street, Richmond, Virginia, 23298, USA. 
Email: pkumnji@vcu.edu

\begin{abstract}
Objective

We explored the association of smoking and GBS colonization among women delivering neonates 35 weeks+.
\end{abstract}

Design

Retrospective chart review

\title{
Setting
}

A large tertiary care inner-city hospital in the southern United States

Population/Sample

803 women pregnant women of term or near term neonates

Methods

The electronic health records of a convenience sample.

\section{Main Outcome Measures}

The outcome variable of interest was maternal GBS colonization. The primary independent variable of interest was tobacco smoking during pregnancy.

\section{Results}

The prevalence of maternal GBS colonization was $32 \%$ among the study population. In the univariate analyses, factors associated with maternal GBS colonization were tobacco smoking during pregnancy (P of trend <0.001), Race (African Americans with the highest colonization rates and East Asians the lowest; $\mathrm{P}<0.001)$, maternal age $<20$ years $(\mathrm{P}=0.006)$, low birthweight $<2500 \mathrm{gm}(\mathrm{P}=0.02)$, maternal drug use $(\mathrm{P}=004)$, and gestational age $<37(\mathrm{P}=0.041)$. Gestational diabetes, parity, and gender were not predictive of GBS colonization. In the multiple logistic regression analysis, Women who smoked during pregnancy were more than twice more likely to be colonized than their non-smoking counterparts $(\mathrm{OR}=2.6 ; 95 \% \mathrm{CI}=1.5-4.6$; $\mathrm{p}<0.001)$. Maternal age was the only other significant predictor with young mothers $<20$ years more than one and a half time more likely to be colonized than their older counterparts $(\mathrm{OR}=1.65 ; 95 \% \mathrm{CI}=1.02-2.68$; $\mathrm{P}=0.04)$.

\section{Conclusion}

Smoking during pregnancy was identified as an independent risk factor for GBS colonization. This is another reason that women should refrain from smoking during pregnancy to avoid risking their babies developing GBS disease.

Keywords. Smoking in Pregnancy, Maternal GBS colonization, Risk Factors.

Tweetable abstract. Smoking and maternal age were confirmed as two very important independent predictors of GBS colonization among women delivering term and near term neonates in a large tertiary care hospital in the southern United States.

\section{Introduction}

Maternal group B streptococcal (GBS) colonization is one of the most important risk factors for GBS disease in neonates. In 2002, the Centers for Disease Control (CDC) recommended universal culture-based screening of all pregnant women between 35-37 weeks gestation in order to treat all those positive for GBS with intrapartum antibiotics prior to delivery to prevent against early onset neonatal GBS sepsis. ${ }^{1}$ Ever since the institution of this policy, the incidence of early onset GBS sepsis has continued to fall dramatically from a rate of $1.5 / 1,000$ to a rate of $0.24 / 1,000{\text { live } \text { births. }^{2}}^{2}$ 
However, the prevalence of maternal GBS colonization among the population in this region has not been recently explored. The colonization rate varies from country to country, the geographic location, and the method used in determining the colonization. In the USA, carriage rates in the 70's and 80's ranged from $20 \%$ to $35 \% .^{3-5}$ In Africa, rates ranged from $20 \%$ to $30 \%{ }^{6-8}$ In Eastern Europe rates of $30+\%$ have also been determined. ${ }^{9}$ In Western Europe rates ranged from a low of $14 \%$ to a high of $36 \% .{ }^{5,10}$ In India the rates were as low as $15 \%,{ }^{11}$ while in Korea, the rate was as low as $8 \% .{ }^{12}$ In Australia, rates as high as $35 \%$ have been demonstrated. ${ }^{13}$ In summary, rates of GBS colonization have remained remarkably stable over the past 40 years.

Potential sociodemographic risk factors for GBS colonization among pregnant women have not been recently explored. Perusal of the literature within the last 2 decades demonstrates a paucity of information on other potential sociodemographic risk factors associated with maternal GBS colonization during pregnancy. One risk factor of GBS colonization of mothers of term or near term neonates not yet adequately explored is tobacco smoke exposure during pregnancy. Tobacco smoke has been shown to be associated with increased colonization of the respiratory, gastrointestinal, and even genital tract with various bacterial pathogens. ${ }^{14-21}$ Because over $10 \%$ of women in the United States smoke during pregnancy, ${ }^{22}$ it is important to determine whether smoking is a risk factor for GBS colonization. We therefore hypothesized that tobacco smoking during pregnancy is independently associated with increased GBS colonization among women delivering term or near term neonates in this tertiary care hospital in Virginia.

\section{Methods}

\section{Design and Study Population}

The study was carried out in a large inner-city tertiary care university teaching hospital in Virginia. Almost 2,000 babies are born each year in this hospital of which about 30\% are Whites, $40 \%$ African Americans and $30 \%$ Hispanics or Latinos. A convenience sample of 803 mother-newborn dyad singletons were retrospectively recruited in the study using electronic health records (EHRs). The data included a sample of patients born from January 1, 2011 to December 31, 2019 divided almost equally yearly (i.e. almost 90 patients selected each year). The IRB of the Virginia Commonwealth University School of Medicine approved the study as expedited.

\section{Variables and Definitions of Terms}

The outcome variable of interest was GBS colonization of pregnant mothers during gestation. GBS colonization status was determined by recto-vaginal swabs at 35-37 weeks gestation and consisted of placement of the genital swab approximately $2 \mathrm{~cm}$ into the vagina followed by placement through the anal sphincter. The result of the test was defined as either positive or negative by the PCR using standard techniques as described. ${ }^{13}$ Tobacco smoking was defined by the number of cigarettes smoked per day during gestation. This variable was accurately recorded by the attending obstetrician during prenatal visits. In the rare instances when this information was missing in the EHR of the obstetrician, e.g. because of lack of prenatal care, the pediatrician usually recorded the smoking status after delivery by direct questioning of the new mother during her Nursery stay. If the mother smoked during pregnancy, the number of cigarettes was also recorded in the mother's EHR by the obstetrician or the pediatrician. Information on tobacco smoking status of all subjects was thus available. Maternal variables abstracted were: age in years, parity, history of gestational diabetes, race, and substance use. Infant factors abstracted were: birthweight in grams, gestational age in weeks, and gender of the newborn baby (male or female). Maternal substance use was defined as any use during pregnancy of various drugs such as cocaine, various opiates (e.g., methadone, OxyContin, buprenorphine (Subutex), cannabinoids, or other illegal substances. These potential risk factors were all gleaned from the literature.

\section{Data Analyses}

A total sample of 803 mother newborn dyad was recruited in the study. The outcome variable of interest was GBS colonization among pregnant women delivering term or near term infants $35+$ weeks gestational 
age. The primary independent variable of interest was active tobacco smoking throughout pregnancy as determined by the number of cigarettes smoked per day. In the univariate analysis, tobacco smoking was categorized as 0 cigarette/day, 1 cigarette/day, 2 cigarettes/day, and $3+$ cigarettes/day respectively for trend analysis. Test of trend was also explored for maternal age. Initially maternal age was empirically categorized into 2 groups $(<20$ year of years versus $20+$ years). A trend analysis for this variable was then conducted to determine whether GBS rates varied by the various maternal age groups. When a clear trend emerged, maternal age was subsequently empirically expanded to 5 groups $(<20,20-24,25-29,30-34$, and $35+)$ to explore whether the trend continued. Tests of trends were also explored for the other independent variables of interest (birthweight, gestational age) but were not significant so these variables were left dichotomized in the univariate analysis. In the multiple logistic regression analyses, all the independent variables of interest were left dichotomized for simplicity of analyses.

Descriptive statistics were conducted. Univariate analysis was conducted to determine if each of the selected variables was associated with maternal GBS colonization using the $\mathrm{X}^{2}$ analysis of comparisons of proportions with Fischer's exact test. Next, a multiple logistic regression analysis was conducted using only the significant variables in the univariate analysis to determine if each of these factors was still predictive of maternal GBS colonization after controlling for the other potential confounders. The SPSS statistical software (IBM, Armonk, NY 2018) was used in the analyses. A p value of $<0.05$ was used as test of significance in all cases.

\section{Results}

\section{Sociodemographic Characteristics}

The average maternal age was 28 years while $11 \%$ of the mothers were $<20$ years. The average gestational age was 39 weeks while $7 \%$ were preterm babies ( $<37$ weeks). The average birthweight was $\sim 3311$ grams while $6 \%$ of all neonates had low birthweights $(<2500 \mathrm{gm})$. In this study almost $12 \%$ of all women smoked during gestation. More than $2 \%$ smoked 1 cigarette per day while almost $10 \%$ smoke two or more cigarettes daily. One mother reported smoking up to 30 cigarettes daily (also see Table 1).

\section{Prevalence of GBS Colonization by Sociodemographic Characteristics}

Among the 803 pregnant included in the study, GBS status of 67 women was unknown and when these were excluded from the analysis, the valid prevalence of GBS was $36 \%$. However, when these missing cases were include, the overall prevalence rate of GBS colonization dropped slightly to $32 \%$. GBS carriage was least prevalent among the none smokers $(32 \%)$ but rose sharply to $53 \%$ if the subjects smoked 1 cigarette/day and the rate almost doubled to $63 \%$ if the subjects smoked $2+$ cigarettes/day ( $\mathrm{p}$ of trend=0.003). When maternal age was categorized into 2 groups (teens vs older), GBS was higher among the teen mothers $(<20$ years) as compared to their older counterparts (20+ years, $\mathrm{P}=0.006$; also see Table 2$)$. Furthermore, when maternal age was categorized into 5 groups, the prevalence of GBS was highest among women $<20$ years (49\%), dropped to $40 \%$ in women $20-24$ years, and $30 \%$ in women 25 to 29 years. However, there was a small spike to $36 \%$ in women $30-35$ years but the rate dropped again to $28 \%$ in women 35 + years. In general, therefore, there was a decreasing trend of GBS colonization with increasing maternal age ( $\mathrm{P}$ of Trend $=0.023$; also see Figure 1). Interestingly, this trend was only true among non-smokers. Among the smokers, however, there was no downward trend of maternal in GBS colonization by maternal age ( $\mathrm{P}$ of Trend $=0.935$; also see Figure 2).

The prevalence of GBS colonization was higher among preterm birth infants ( $<37$ weeks gestational age) as compared to their term birth counterparts ( 37 weeks $+; \mathrm{P}=0.041$ ). Mothers of low birth weight infants were $(<2500$ grams) were more likely to be colonized by GBS $(55.2 \%)$ than mothers with heavier or normal birth weight babies $(2500+$ grams; $34.2 \%, \mathrm{P}=0.02)$.

GBS colonization varied widely among the racial groups and was lowest among Asian /Pacific Island Americans $(22 \%)$ as compared to the Latinos (26\%), White Americans (31\%) or African American $(49 \%, \mathrm{P}<0.001)$. Furthermore, the proportion of colonization was more prevalent among women with any history of substance use $(54 \%)$ as compared to those without any use $(35 \% ; \mathrm{P}=0.004)$. Thus, of the nine variables explored in 
this study, only 3 viz. gestational diabetes mellitus, parity, and gender were not predictive of GBS carriage (also see Table 2).

\section{Multiple Logistic Regression of Factors Associated with GBS Colonization}

All the 6 variables significantly associated with GBS colonization in the univariate analyses (smoking, maternal age, birthweight, gestational age, race, and use of substance) were now selected for inclusion in the multiple logistic regression analysis. Tobacco smoking was by far the most significant predictor of GBS colonization even after controlling for the other confounders ( $\mathrm{OR}=2.6,95 \% \mathrm{CI}$ : $1.53-4.34 ; \mathrm{P}<0.001$, also see Table 3). The only other risk factor independently associated with GBS colonization was maternal age $<$ 20 years $(\mathrm{P}=0.041)$.

\section{Discussion}

\section{Main Findings}

There were three important findings in this study: 1) Almost a third of all women delivering term or near neonates were colonized with GBS in this hospital; 2) even after controlling for various confounders, smoking during pregnancy was more than twice more likely to result in GBS colonization among pregnant women of term or near term neonates.; 3) teen mothers less than 20 years had the highest rates of GBS colonization and the rates steadily decreased with age with the lowest rates occurring among the oldest mothers 35 year+. Interestingly this inverse relationship was only true for women who were nonsmokers.

\section{Interpretations}

This high prevalence of GBS colonization found in our study is consistent with previous studies in the USA and elsewhere. ${ }^{3-11}$ The lowest rates were observed mainly in some East Asian nations. ${ }^{5,11,12}$ The acrosscountry differences may be due to differences in techniques. ${ }^{23-25}$ PCR testing after broth enrichment has been has been shown to be a reliable and is now the standard method for GBS testing. ${ }^{24}$ However, testing conducted intrapartum may show somewhat lower prevalence rates as compared to antepartum testing. ${ }^{25}$ If this is so, then there may be excessive use of intrapartum prophylactic antibiotics to prevent GBS sepsis in neonates. Unfortunately, intrapartum testing is not yet practical since it can take up to 2 to 3 days for the results of tests to be made available whereas knowing the results prior to delivery is very important to make a decision to treat prophylactically or not. Hopefully, new rapid PCR tests are being developed for such a purpose. ${ }^{25}$ In spite of the dramatic drop of early onset neonatal GBS sepsis in the United States, the reasons for the persisting high prevalence rates of GBS colonization during pregnancy throughout the past 4 decades need to be further explored.

This study further confirms that, potentially, more than a third of all women were eligible to receive intrapartum prophylactic antibiotics prior to delivery. This is indeed a high rate of pre-delivery antibiotics exposure of term or near term neonates. Several authors have recently suggested that at least $40 \%$ of children may be exposed to intrapartum antibiotics. ${ }^{26,27}$ Although intrapartum antibiotic prophylaxis have successfully reduced the incidence of GBS sepsis in neonates, the dangers of such prophylaxis are concerning. ${ }^{28}$ For instance, intrapartum antibiotic prophylaxis have been associated with complications such as increased prevalence of atopic dermatitis, ${ }^{29}$ antimicrobial resistance, ${ }^{30}$ and changes in the neonatal gut microbiota. ${ }^{31-33}$

The prevalence of active tobacco smoking among pregnant women in this study was $12 \%$, and this is consistent with recent national trends. ${ }^{22}$ However, in our study, the intensity of smoking during pregnancy was rather low and most women who smoked admitted to smoking no more than 3 cigarettes each day although this may be largely an underestimate. Since this was a retrospective study the assumption is that women who admitted to smoking actually smoked throughout pregnancy. The study may, therefore, not take account of those who stopped smoking sometime during pregnancy or those who only initiated smoking sometime during pregnancy.

Few studies in the literature have explored the impact of smoking during pregnancy on GBS colonization. Our study was also able to demonstrate a significant dose-response relationship suggesting that this was 
not just a spurious finding. In the United States, Terry et al. ${ }^{34}$ were the first to show that smoking during pregnancy was predicted of GBS colonization but the authors did not perform a multivariable analysis to control for other confounders to determine if smoking was independently predictive. Edwards and colleagues, 35 in a large retrospective study, recently demonstrated that smoking was also predictive of GBS colonization in the in the univariate analysis but not in the multiple regression analysis. However, smoking was not the primary independent variable of their study. Two studies respectively from Korea and China, ${ }^{12,}{ }^{36}$ failed to demonstrate an association of smoking during pregnancy and GBS colonization. However smoking was also not the primary independent variable of interest of these studies and there were was the additional problem of smallness of numbers in some cells. Our finding that smoking during pregnancy was predictive of GBS colonization during pregnancy is consistent with a smaller study from Iran. ${ }^{37}$ However, their study population was different as it also included preterm neonates that were excluded in our current study. Surprisingly, Regan and colleagues demonstrated in 1991 that smoking was rather protective of GBS colonization. ${ }^{38}$ The authors offered no biological plausibility of their finding. However, only women delivering preterm neonates ( $<36$ weeks) were enrolled in the latter study whereas our study focused only on term or near term neonates. We speculate that the population of women delivering term babies may be quite different from the population delivering only preterm babies.

The finding that tobacco smoke exposure during pregnancy is an independent risk factor for increased GBS colonization has significant public health implications. Because smoking exposure is a modifiable risk factor, women can be counseled to stop smoking during pregnancy in order to reduce colonization with this organism which can result in GBS sepsis in their newborn baby. The association between tobacco smoking and increased GBS colonization during pregnancy is biologically plausible. We speculate that tobacco smoke exposure during pregnancy may actually enhance the colonization of GBS in the gastrointestinal and the genital tracts. Indeed, previous studies have shown that tobacco smoke exposure is associated with increased colonization of the respiratory and genital tract with pathogenic bacteria, ${ }^{39-41}$ possibly through alteration of the microbiome. ${ }^{17,19,41}$ Tobacco smoke contains more than 4,500 chemical intoxicants ${ }^{42}$ many of which can result in increased suppression or modulation of both active and passive immune response. ${ }^{43}$ For instance, nicotine, an important component of tobacco smoke, has been shown to enhance the adherence of bacteria in mucous membranes of the respiratory tract leading to easy penetration of bacteria into the tissues to cause infections. ${ }^{44}$ This could also be true of the genital tract of pregnant women where nicotine could actually result in the persistence of GBS in the mucous membranes of the gastrointestinal and genital tracts. Indeed some studies have actually demonstrated higher nicotine levels in the cervical mucous membranes of smokers as compared to non-smokers. ${ }^{45,46}$ In another study, nicotine of the cervical mucus of female smokers resulted in DNA damage of epithelial cells of these women resulting in easy penetration of bacteria into the adjacent tissues. ${ }^{47}$ It can be speculated that the overall effect of tobacco smoke is the alteration of the microbiome of the female genital tract resulting in increased prevalence of pathogenic microorganisms such as GBS in the present study.

To our knowledge only a few studies in the United States have been conducted in recent years to determine potential sociodemographic risk factors associated with this rather high colonization rates among pregnant women. In the '70's Anthony et al showed that Mexican Americans had the lowest rates as compared to Whites or Blacks. ${ }^{48}$ In our study, black mothers had the highest rates as compared to White or Hispanic/Latino mothers. These findings are consistent with those of Regan and colleagues whose study was conducted almost 30 years ago. ${ }^{38}$ The finding that younger mothers had significantly higher rates of GBS colonization was consistent with one previous study conducted more than 40 years ago by Anthony and colleagues. ${ }^{48}$ They demonstrated that younger mothers had higher rates of GBS colonization than their older counterparts. Indeed, GBS sepsis in neonates has also been shown to be more common among young mothers $<20$ years, as demonstrated by Schuchat et al. ${ }^{49,50}$ This may be explained by the fact that young mothers also have higher rates of GBS colonization than their older counterparts as shown in our study. However, 10 years after the study by Anthony et al, ${ }^{48}$ Regan et al ${ }^{38}$ showed that GBS colonization was less common among women less than 20 years of age even after controlling for the other sociodemographic confounders. The difference in findings between the two studies may be due to the fact that cultures for 
GBS were obtained very early in gestation (23-26 weeks gestation) in the latter study, whereas the current recommendation is to obtain cultures at $35-37$ weeks of gestation. ${ }^{1}$ Again as stated above, our study clearly demonstrates that maternal age was only predictive of GBS colonization among the non-smoking women. Non-smokers $<20$ years had the highest GBS colonization rate while those $>35$ years of age had the lowest rate $(\mathrm{P}$ of Trend $=0.02$; also see Fig 1$)$.

Limitations and Significance

This study has several limitations. First the retrospective nature of the data implies that there is no causality attributed to the findings. Second, because the study only involved subjects recruited from one local hospital, there may therefore be lack of both internal and external validity of the findings as this sample was not necessarily representative of the population of the state or of the nation. Third, the information of tobacco smoking was retrospectively obtained so there is likelihood of misclassification bias. The association between tobacco smoking and GBS colonization would have been even stronger if the smoking status was determined objectively by the use of a biomarker such as serum or urine cotinine levels. This may have reduced the likelihood of misclassification bias of the smoking status of the subjects. However, some of the findings are consistent with previous works. Fourthly, we were not able to control for all the confounders such as obesity and the frequency of sexual relationships which have been shown in some studies to be predictive of GBS colonization. ${ }^{51}$ The significance of this study lies in the fact that this is the first robust study with the main focus of determining the impact of tobacco smoke on GBS colonization on women of term or near neonates. In other studies GBS was not the main focus and a test of trend was not explored.

\section{SUMMARY, CONCLUSION, AND RECOMMENDATION}

The prevalence of GBS colonization was rather high among the study population. This is one of the few studies to clearly determine that smoking during pregnancy is an independent predictor of GBS colonization in women of term or near term neonates. GBS colonization was highest among the youngest mothers and tended to decrease with age especially among non-smoking mothers. This is another reason why women should be counseled to stop smoking if they are pregnant in order to avoid risking their newborn from developing GBS disease.

\section{Acknowledgement}

We wish to thank the staff of the Department of General Pediatrics of the Children's Hospital of Richmond for their help in bringing this work to fruition

\section{Availability of data}

Data are fully available on request in full compliance with the ethical and governance standards under which this research was conducted.

\section{Disclosure of interest}

None of the authors has any conflict of interest to declare.

\section{Contribution to authorship}

PK initiated the study, recruited subjects, conducted data management, analyses, and final write-up.

LM was involved in the data management, analysis, editing, and final write-up.

JP was involved in analyses, final write-up, and editing.

AR was involved in data analysis, final write-up, and editing.

RW recruited subjects, conducted data management, and was involved in editing and final write-up.

All authors approved the final manuscript as submitted and agree to be accountable for all aspects of the work. 


\section{Details of Ethics Approval}

The Institutional Review Board (IRB) of the Virginia Commonwealth University School of Medicine approved the study as expedited (approval number: HM15338; date of approval: April 1, 2011).

\section{Funding}

This study was not funded

\section{REFERENCES}

1. Schrag S, Gorwitz R, Fultz-Butts K, Schuchat A. Prevention of perinatal group B streptococcal disease. Revised guidelines from CDC. MMWR Recomm Rep. 2002 Aug 16;51(RR-11):1-22. PubMed PMID: 12211284.

2. National Center for Health Statistics. Vital Statistics Birth Data File, 2015. All-county file data file and documentation. 2016.

3. Dillon HC Jr, Gray E, Pass MA, Gray BM. Anorectal and vaginal carriage of group B streptococci during pregnancy. J Infect Dis. 1982 Jun;145(6):794-9.

4. Hoogkamp-Korstanje JA, Gerards LJ, Cats BP. Maternal carriage and neonatal acquisition of group B streptococci. J Infect Dis. 1982 Jun;145(6):800-3. PubMed

5. Russell NJ, Seale AC, O'Driscoll M, O'Sullivan C, Bianchi-Jassir F, Gonzalez-Guarin J, Lawn JE, Baker CJ, Bartlett L, Cutland C, Gravett MG, Heath PT, Le Doare K, Madhi SA, Rubens CE, Schrag S, Sobanjo-Ter Meulen A, Vekemans J, Saha SK, Ip M; GBS Maternal Colonization Investigator Group. Maternal Colonization With Group B Streptococcus and Serotype Distribution Worldwide: Systematic Review and Meta- analyses. Clin Infect Dis. 2017 Nov 6;65(suppl_2):S100-S111. Doi: 10.1093/cid/cix658. Review. PubMed PMID: 29117327; PubMed Central PMCID: PMC5848259.

6. Joachim A, Matee MI, Massawe FA, Lyamuya EF. Maternal and neonatal colonisation of group B streptococcus at Muhimbili National Hospital in Dar es Salaam, Tanzania: prevalence, risk factors and antimicrobial resistance. BMC Public Health. 2009 Dec 1;9:437. doi: 10.1186/1471-2458-9-437. PubMed PMID:

7. Seale AC, Koech AC, Sheppard AE, Barsosio HC, Langat J, Anyango E, Mwakio S, Mwarumba S, Morpeth SC, Anampiu K, Vaughan A, Giess A, Mogeni P, Walusuna L, Mwangudzah H, Mwanzui D, Salim M, Kemp B, Jones C, Mturi N, Tsofa B, Mumbo E, Mulewa D, Bandika V, Soita M, Owiti M, Onzere N, Walker AS, Schrag SJ, Kennedy SH, Fegan G, Crook DW, Berkley JA. Maternal colonization with Streptococcus agalactiae and associated stillbirth and neonatal disease in coastal Kenya. Nat Microbiol. 2016 May 23;1(7):16067. Doi: 10.1038/nmicrobiol.2016.67. PubMed PMID: 27572968; PubMed Central PMCID: PMC4936517.

8. Slotved HC, Dayie NTKD, Banini JAN, Frimodt-Møller N. Carriage and serotype distribution of Streptococcus agalactiae in third trimester pregnancy Jul 21;17(n Ghana. BMC Pr.1186/s12884-birth. 2017 PubMed PMID: 2873 doi: 10.1186/s128al PMCID: 9-0. PubMed PMID: 28732495; PubMed Central PMCID: PMC5520380.

9. Kadanali A, Altoparlak U, Kadanali S. Maternal carriage and neonatal colonisation of group B streptococcus in eastern Turkey: prevalence, risk factors and antimicrobial resistance. Int J Clin Pract. 2005 Apr;59(4):437-40. PubMed

10. Barcaite E, Bartusevicius A, Tameliene R, Kliucinskas M, Maleckiene L, Nadisauskiene R. Prevalence of maternal group B streptococcal colonisation in European countries. Acta Obstet Gynecol Scand. 2008;87(3):260-71. doi: 10.1080/000163408019087

11. Chaudhary M, Rench MA, Baker CJ, Singh P, Hans C, Edwards MS. Group B Streptococcal Colonization Among Pregnant Women in Delhi, India. Pediatr Infect Dis J. 2017 Jul;36(7):665-669. Doi: 10.1097/INF.0000000000001514. PubMed PMID: 28027278

12. Kim EJ, Oh KY, Kim MY, et al. Risk factors for group B streptococcus colonization among pregnant women in Korea. Epidemiol Health . 2011;33:e2011010. doi:10.4178/epih/e2011010

13. Gilbert GL, Hewitt MC, Turner CM, Leeder SR. Epidemiology and predictive values of risk factors for neonatal group B streptococcal sepsis. Aust N Z J Obstet Gynaecol. 2002 Nov;42(5):497-503. PubMed 
PMID: 12495094.

14. Verani JR, McGee L, Schrag SJ; Division of Bacterial Diseases, National Center for Immunization and Respiratory Diseases, Centers for Disease Control and Prevention (CDC). Prevention of perinatal group B streptococcal disease-revised guidelines from CDC, 2010. MMWR Recomm Rep. 2010 Nov 19;59(RR-10):1-36. PubMed PMID: 21088663.

15. Brook I, Gober AE. Recovery of potential pathogens in the nasopharynx of healthy and otitis media-prone children and their smoking and nonsmoking parents. Ann Otol Rhinol Laryngol. 2008 Oct;117(10):727-30. PubMed PMID: 18998498.

16. Brook I. Effects of exposure to smoking on the microbial flora of children and their parents. Int J Pediatr Otorhinolaryngol. 2010 May;74(5):447-50. doi: 10.1016/j.ijporl.2010.01.006. Epub 2010 Feb 2. Review. PubMed PMID: 20129680.

17. Brook I. The impact of smoking on oral and nasopharyngeal bacterial flora. J Dent Res. 2011 Jun;90(6):704-10. doi: 10.1177/0022034510391794. Review. PubMed PMID: 21558542.

18. Shen P, Whelan FJ, Schenck LP, McGrath JJC, Vanderstocken G, Bowdish DME, Surette MG, Stämpfli MR. Streptococcus pneumoniae Colonization Is Required To Alter the Nasal Microbiota in Cigarette Smoke-Exposed Mice. Infect Immun. 2017 Sep 20;85(10). pii: e00434-17. doi: 10.1128/IAI.00434-17. Print 2017 Oct. PubMed PMID: 28760931; PubMed Central PMCID: PMC5607400.

19. Voss M, Wonnenberg B, Honecker A, Kamyschnikow A, Herr C, Bischoff M, Tschernig T, Bals R, Beisswenger C. Cigarette smoke-promoted acquisition of bacterial pathogens in the upper respiratory tract leads to enhanced inflammation in mice. Respir Res. 2015 Mar 20;16:41. doi: 10.1186/s12931-0150204-8. PubMed PMID: 25890119; PubMed Central PMCID: PMC4395896.

20. Nelson TM, Borgogna JC, Michalek RD, Roberts DW, Rath JM, Glover ED, Ravel J, Shardell MD, Yeoman CJ, Brotman RM. Cigarette smoking is associated with an altered vaginal tract metabolomic profile. Sci Rep. 2018 Jan 16;8(1):852. doi: 10.1038/s41598-017-14943-3. PubMed PMID: 29339821; PubMed Central PMCID: PMC5770521.

21. Voss M, Wonnenberg B, Honecker A, Kamyschnikow A, Herr C, Bischoff M, Tschernig T, Bals R, Beisswenger C. Cigarette smoke-promoted acquisition of bacterial pathogens in the upper respiratory tract leads to enhanced inflammation in mice. Respir Res. 2015 Mar 20;16:41. doi: 10.1186/s12931-0150204-8. PubMed PMID: 25890119; PubMed Central PMCID: PMC4395896.

22. Curtin SC, Mathews TJ. Smoking prevalence and cessation before and during pregnancy: Data from the birth certificate, 2014. National vital statistics reports; vol 65 no 1. Hyattsville, MD: National Center for Health Statistics. 2016

23. Park JS, Cho DH, Yang JH, Kim MY, Shin SM, Kim EC, Park SS, Seong MW. Usefulness of a rapid real-time PCR assay in prenatal screening for group B streptococcus colonization. Ann Lab Med. 2013 Jan;33(1):39-44. doi: 10.3343/alm.2013.33.1.39. Epub 2012 Dec 17.

24. Busetti M, D'Agaro P, Campello C. Group B streptococcus prevalence in pregnant women from NorthEastern Italy: advantages of a screening strategy based on direct plating plus broth enrichment. J Clin Pathol. 2007 Oct;60(10):1140-3. Epub 2006 Dec 20.

25. Church DL, Baxter H, Lloyd T, Larios O, Gregson DB. Evaluation of StrepBSelectChromogenic Medium and the Fast-Track Diagnostics Group B Streptococcus (GBS) Real-Time PCR Assay Compared to Routine Culture for Detection of GBS during Antepartum Screening. J Clin Microbiol. 2017 Jul;55(7):2137-2142. doi:10.1128/JCM.00043-17. Epub 2017 Apr 26. PubMed PMID: 28446575; PubMed Central

26. Ledger WJ, Blaser MJ. Are we using too many antibiotics during pregnancy?BJOG.2013 Nov;120(12):1450-2. doi: 10.1111/1471-0528.12371.

27. Turrentine MA. Antenatal antibiotics: too much, too little, or just right? BJOG 2013;120:1453-1455

28. Seedat F, Stinton C, Patterson J, Geppert J, Tan B, Robinson ER, McCarthy ND, Uthman OA, Freeman K, Johnson SA, Fraser H, Brown CS, Clarke A, Taylor-Phillips S. Adverse events in women and children who have received intrapartum antibiotic prophylaxis treatment: a systematic review. BMC Pregnancy Childbirth. 2017 Jul 26;17(1):247. doi: 10.1186/s12884-017-1432-3. Review. PubMed PMID: 28747160; 
29. Wohl DL, Curry WJ, Mauger D, Miller J, Tyrie K. Intrapartum antibiotics and childhood atopic dermatitis. J Am Board Fam Med. 2015 Jan-Feb;28(1):82-9. doi:10.3122/jabfm.2015.01.140017. PubMed PMID: 25567826; PubMed Central PMCID

30. Ashkenazi-Hoffnung L, Melamed N, Ben-Haroush A, Livni G, Amir J, Bilavsky E. The association of intrapartum antibiotic exposure with the incidence and antibiotic resistance of infantile late-onset serious bacterial infections. Clin Pediatr (Phila). 2011 Sep;50(9):827-33. doi: 10.1177/0009922811406260. PubMed

31. Nelson TM, Borgogna JC, Michalek RD, Roberts DW, Rath JM, Glover ED, Ravel J, Shardell MD, Yeoman CJ, Brotman RM. Cigarette smoking is associated with an altered vaginal tract metabolomic profile. Sci Rep. 2018 Jan 16;8(1):852. doi: 10.1038/s41598-017-14943-3. PubMed PMID: 29339821; PubMed Central PMCID:

32. Aloisio I, Mazzola G, Corvaglia LT, Tonti G, Faldella G, Biavati B, Di Gioia D. Influence of intrapartum antibiotic prophylaxis against group B Streptococcus on the early newborn gut composition and evaluation of the anti-Streptococcus activity of Bifidobacterium strains. Appl Microbiol Biotechnol. 2014 Jul;98(13):6051-60. doi: 10.1007/s00253-014-5712-9. Epub 2014 Apr 1. PubMed PMID

33. Arboleya S, Sánchez B, Solís G, Fernández N, Suárez M, Hernández-Barranco AM, Milani C, Margolles A, de Los Reyes-Gavilán CG, Ventura M, Gueimonde M. Impact of Prematurity and Perinatal Antibiotics on the Developing Intestinal Microbiota: A Functional Inference Study. Int J Mol Sci. 2016 Apr 29;17(5). pii: E649. doi: 10.3390/ijms17050649. PubMed PMID: 27136545; PubMed Central PMCID: PMC4881475.

34. Terry RR, Kelly FW, Gauzer C, Jeitler M. Risk factors for maternal colonization with group B betahemolytic streptococci. J Am Osteopath Assoc. 1999 Nov;99(11):571-3. PubMed PMID: 10612953.

35. Edwards JM, Watson N, Focht C, Wynn C, Todd CA, Walter EB, Heine RP, Swamy GK.Group B Streptococcus (GBS) Colonization and Disease among Pregnant Women: A Historical Cohort Study. Infect Dis Obstet Gynecol. 2019 Feb 3;2019:5430493. doi:10.1155/2019/5430493. eCollection 2019. PubMed PMID: 30853787; PubMed Central PMCID: PMC6378061.

36. Chen J, Fu J, Du W, Liu X, Rongkavilit C, Huang X, Wu Y, Wang Y, McGrath E. Group B streptococcal colonization in mothers and infants in western China: prevalences and risk factors. BMC Infect Dis. 2018 Jul 3;18(1):291. doi:10.1186/s12879-018-3216-4. PubMed PMID: 29970020; PubMed Central PMCID: PMC6029028.

37. Darabi R, Tadi S, Mohit M, et al. The prevalence and risk factors of group B streptococcus colonization in Iranian pregnant women.Electron Physician . 2017;9(5):4399-4404. Published 2017 May 25. doi:10.19082/4399

38. Regan JA, Klebanoff MA, Nugent RP. The epidemiology of group B streptococcal colonization in pregnancy. Vaginal Infections and Prematurity Study Group. Obstet Gynecol. 1991 Apr;77(4):604-10. PubMed PMID: 2002986.

39. Huneeus A, Schilling A, Fernandez MI. Prevalence of Chlamydia Trachomatis, Neisseria Gonorrhoeae, and Trichomonas Vaginalis Infection in Chilean Adolescents and Young Adults. J Pediatr Adolesc Gynecol. 2018 Aug;31(4):411-415. doi:10.1016/j.jpag.2018.01.003. Epub 2018 Feb 1. PubMed PMID: 29409759.

40. Greenberg D, Givon-Lavi N, Broides A, Blancovich I, Peled N, Dagan R. The contribution of smoking and exposure to tobacco smoke to Streptococcus pneumonia and Haemophilus influenzae carriage in children and their mothers. Clin Infect Dis. 2006 Apr 1;42(7):897-903. Epub 2006 Feb 16. PubMed PMID: 16511750.

41. Lee SH, Yun Y, Kim SJ, Lee EJ, Chang Y, Ryu S, Shin H, Kim HL, Kim HN, Lee JH. Association between cigarette smoking status and composition of gut microbiota: population-based cross-sectional study. J Clin Med. 2018;7:282. doi: 10.3390/jcm7090282. [PMC free article] [PubMed]

42. Department of Health and Human Services. How Tobacco Smoke Causes Disease: The Biology and Behavioral Basis for Smoking-Attributable Disease: A Report of the Surgeon General. Atlanta, GA: U.S. Department of Health and Human Services, Centers for Disease Control and Prevention, National Center for Chronic Disease Prevention and Health Promotion, Office on Smoking and Health, 2010. 
43. Kum-Nji P, Meloy L, Herrod HG. Environmental tobacco smoke exposure: prevalence and mechanisms of causation of infections in children. Pediatrics. 2006 May;117(5):1745-54. Review. PubMed PMID: 16651333.

44. El Ahmer OR, Essery SD, Saadi AT, Raza MW, Ogilvie MM, Weir DM, Blackwell CC. The effect of cigarette smoke on adherence of respiratory pathogens to buccal epithelial cells. FEMS Immunol Med Microbiol. 1999 Jan;23(1):27-36.

45. McCann MF, Irwin DE, Walton LA, Hulka BS, Morton JL, Axelrad CM. Nicotine and cotinine in the cervical mucus of smokers, passive smokers, and nonsmokers. Cancer Epidemiol Biomarkers Prev. 1992 Jan-Feb;1(2):125-9. PubMed PMID: 1306094.

46. Hellberg D, Nilsson S, Haley NJ, Hoffman D, Wynder E. Smoking and cervical intraepithelial neoplasia: nicotine and cotinine in serum and cervical mucus in smokers and nonsmokers. Am J Obstet Gynecol. 1988 Apr;158(4):910-3. PubMed PMID: 3364502.

47. Simons, A. M., Phillips, D. H. \& Coleman, D. V. Damage to DNA in Cervical Epithelium Related to Smoking. Tobacco. 49, 186 (1994).

48. Anthony BF, Okada DM, Hobel CJ. Epidemiology of group B Streptococcus: longitudinal observations during pregnancy. J Infect Dis. 1978 May;137(5):524-30.

49. Schuchat A, Deaver-Robinson K, Plikaytis BD, Zangwill KM, Mohle-Boetani J, Wenger JD. Multistate case-control study of maternal risk factors for neonatal group B streptococcal disease. The Active Surveillance Study Group. Pediatr Infect Dis J. 1994 Jul;13(7):623-9. PubMed PMID: 7970951.

50. Schuchat A, Zywicki SS, Dinsmoor MJ, Mercer B, Romaguera J, O’Sullivan MJ,Patel D, Peters MT, Stoll B, Levine OS. Risk factors and opportunities for prevention of early-onset neonatal sepsis: a multicenter case-control study. Pediatrics. 2000 Jan;105(1 Pt 1):21-6.

51. Meyn LA, Moore DM, Hillier SL, Krohn MA. Association of sexual activity with colonization and vaginal acquisition of group B Streptococcus in nonpregnant women. Am J Epidemiol. 2002 May 15;155(10):949-57. PubMed PMID: 11994235.

\section{Hosted file}

GBS Tables to BJOG.docx available at https://authorea.com/users/321025/articles/450376-gbscolonization-prevalence-and-the-impact-of-smoking-in-women-delivering-term-or-near-termneonates-in-a-large-tertiary-care-hospital-a-retrospective-chart-review

\section{Hosted file}

GBS BJOG Figs 1 \& 2.docx available at https://authorea.com/users/321025/articles/450376-gbscolonization-prevalence-and-the-impact-of-smoking-in-women-delivering-term-or-near-termneonates-in-a-large-tertiary-care-hospital-a-retrospective-chart-review 